\title{
Debido proceso material y el control difuso de constitucionalidad: una revisión desde la nueva acción de inaplicabilidad
}

* Abogada, Ayudante del Departamento de Derecho Público de la Pontificia Universidad Católica de Cbile.

\section{El problema inicial}

Publicada la ley 20.050 el 26 de agosto de 2005, comenzó la preocupación académica en torno a las nuevas tareas encomendadas a nuestro Tribunal Constitucional, en especial, respecto a la facultad que ahora le otorga el artículo $93 \mathrm{n}^{\circ} 6$, esto es, la de conocer y resolver la Acción (o Recurso) de Inaplicabilidad.

Copiosas dudas transitaban en cuanto a la decisión del Tribunal Constitucional respecto a aquella nueva y trascendente competencia, que lo colocaba en disyuntiva, toda vez que el Legislador Orgánico Constitucional no establecía el procedimiento para el ejercicio de la nueva atribución, y dado lo dispuesto en el artículo $19 \mathrm{n}^{\circ} 3$ inciso $5^{\circ}$ y el principio de reserva legal, el TC debía esperar a la dictación de la respectiva Ley Orgánica', para poder dar curso a las acciones de inaplicabilidad. Ya lo planteaba la doctrina en los siguientes términos: "La Reforma Constitucional exige que la nueva Ley Orgánica del Tribunal Constitucional establezca siempre las garantías del debido proceso - señaladas por la jurisprudencia de la Excelentísima Corte Suprema- en los juicios de inaplicabilidad e inconstitucionalidad de la leyes"2, de manera que comen-

1 El artículo 92 inciso final de la Constitución, es el que contiene el mandato al legislador de dictar la correspondiente Ley Orgánica Constitucional. Dicho precepto reza: "Una ley orgánica constitucional determinará su organización, funcionamiento, procedimientos y fijará la planta, régimen de remuneraciones y estaturo de su personal”.

2 Varas Alfonso, Paulino, "Jurisprudencia de la Excma. Corte Suprema sobre las garantías del debido proceso en la ley orgánica del Tribunal Constitucional, según la reforma de 2005 en los juicios de inaplicabilidad e inconstitucionalidad", en Revista de Derecho Público No 68, Santiago, Universidad de Chile, 2006, Pág. 36. 
zar la pertinente tramitación de las inaplicabilidades, estaba al filo de ir en contra del mandato constitucional del debido proceso.

No obstante las dudas aludidas, la inconstitucionalidad se planteaba más bien, desde otro frente. Como se ha venido exponiendo desde hace algún tiempo, cuando el legislador se abstiene de estatuir las normas para dar plena ejecución a la Constitución, viene por esa ruta a violentarla gravemente. En otras palabras, es claro que la Constitución puede ser vulnerada no sólo por acción, sino también, por omisión; concretamente en este último caso, cuando no se actúa a pesar de la expresa previsión constitucional dirigida a que se lo haga, o cuando se regula de modo deficiente. Este vicio de inconstitucionalidad por omisión, en coherencia con la supremacía constitucional, "debía ser superado, sobre la base de que no pueden admitirse más las añejas afirmaciones que se hacían acerca de los postulados incumplidos o de las cláusulas programáticas. Por consiguiente, transcurrido un plazo prudencial, seguramente prolongado, sin que el órgano público cuya actuación requiere la Carta Fundamental la haya cumplido, entonces los tribunales deben infundir eficacia al principio de fuerza normativa directa de la Constitución y decidir el conflicto con sujeción a ésta y dentro de ella" ${ }^{3}$ La razón de fondo: "Un Estado de Derecho puede sobrevivir al hecho que ciertas infracciones a la Carta Fundamental logren superar las barreras de control, pero el verdadero problema se produce cuando las violaciones a la Constitución se multiplican, y los órganos jurisdiccionales se revelan incapaces de impedir el triunfo de la inconstitucionalidad. Ese sí sería el triunfo de la muerte: la muerte del Estado de Derecho democrático".

\section{La hermenéutica como solución}

En general, abordar una solución para el vicio de inconstitucionalidad por omisión, resulta ser siempre un problema de gran dificultad en el derecho comparado ${ }^{5}$. En estos horizontes de opaca tonalidad para la supremacía constitucional, es donde la interpretación constitucional cobra su mayor relevancia, y se presenta como una solución para un vicio de compleja, sensible y democrática dificultad, siendo menester el tener siempre presente, que "la interpretación constitucional debe regirse por las reglas propias de la hermenéutica constitucional, que son especiales, diferentes a las del derecho privado y ya vastamente conocidas, por la amplia cobertura que tienen en la justicia constitucional". 6

3 Cea Egaña, José Luis, "Panorama de un siglo de cambios en la Teoría Constitucional", Conferencia Inaugural del Curso de Interpretación Constitucional, dicrada en la Facultad de Derecho de la Universidad de Los Andes, Santiago, 20 de octubre de 2003, Pág. 18.

4 Zapata Larrain, Patricio, "La jurisprudencia del Tribunal Constitucional", Ed. Biblioteca Americana Universidad Andrés Bello, Santiago, 2002, Pág. 95.

5 Véase en esta materia un interesante articulo escrito por el profesor Victor Bazán, respecto a las omisiones constitucionales y su posible corrección, en Revista Estudios Constitucionales, Santiago, Centro de Estudios Constitucionales, 2006.

- Colombo Campbell, Juan, "El Debido Proceso Constitucional", en Cuadernos de Tribunal Constitucional No 32, Santiago, Tribunal Constitucional, 2006, Pág. 73. 
Con precisión, la doctrina constitucional se hace cargo de una de aquellas reglas que son propias de la aludida interpretación especializada, expresándola en los siguientes términos: "No podrá interpretarse una disposición de modo que el resultado pugne con las Bases Fundamentales, (...). En primer término, debe reconocérsele a las Bases de la Institucionalidad su calidad de principios ordenadores y directrices de toda la Constitución (...)"7. En armonía con aquella pauta interpretativa, el T.C. decidió dar tramitación a las acciones de inaplicabilidad. Sus fundamentos se centraron en los principios de inexcusabilidad, supremacía constitucional, fuerza normativa, aplicabilidad directa de la Constitución, complementando con argumentos extraídos de la ley $17.997^{8}$. Y es del caso considerar que aquella decisión significó el fiel cumplimiento de la denominada labor de "Guardián Supremo de la Constitución", toda vez que, como bien expone el Constitucionalista José Luis Cea Egaña: "Los principios son disposiciones jurídicas básicas y de gran generalidad que se irradian sobre todas la normas, imprimiéndoles sentido y sirviendo de criterio correcto para su exacta comprensión. Respetar íntegramente los principios constitucionales es, en consecuencia, la clave para conservar la Constitución. Violar explícita o disimuladamente dichos principios, aunque sea pretextando circunstancias extraordinarias, es destruir la Constitución. Por eso, si el legislador transgrede un principio, ofende no sólo a las normas constitucionales que lo concretan, sino que además y, sobre todo, incurre en la más grave inconstitucionalidad, cual es la insurgencia contra todo el sistema jurídico, subversión de sus valores fundamentales"?

\section{Hacia una cabal comprensión del debido proceso}

Como se desprende de la existencia de los elementos mencionados en las líneas anteriores -supremacía constitucional, aplicabilidad directa, fuerza normativa, justicia constitucional-, se ha abierto paso fuerte a un nuevo paradigma jurídico, cuyo núcleo y proyección es y se encuentra en la constitucionalización del derecho, es decir, en la invasión y el consiguiente condicionamiento de todo el ordenamiento jurídico por parte de la Constitución.

Se requiere entonces dar una mirada a la institución del debido proceso revisado desde la influencia de dicho fenómeno saludablemente saturador, y una obligada distinción fundamental es el resultado que arroja la institución una vez evaluada, en orden a que: "Si bien es cierto que la ley debe fijar los trámites del proceso, no lo es menos que siem-

7 Zapata Larraín, Patricio, "La interpretación de la Constitución", en Revista Chilena de Derecho, Santiago, Volumen 17 No 1, 1990, pp. 173, 174.

3 Ley Orgánica Constitucional del Tribunal Constitucional publicada el 19 de mayo de 1981.

- Cea Egaña, José Luis, "Hermenéurica Constitucional, Soberanía Legal y Discrecionalidad Adminiscrativa”, en Revista Chilena de Derecho, Volumen 11, No 1, Santiago, Pontificia Universidad Católica de Chile, 1984, Pág. 7. 
pre ha de hacerlo en forma racional y asegurando que sea sustantivamente justo" ${ }^{10} \mathrm{De}$ manera que son dos aspectos los que imperativamente han de distinguirse en el debido proceso, pues "En su expresión propiamente adjetiva, se le concibe como el conjunto de reglas que el legislador y el ejecutor de la ley deben observar en el cumplimiento de sus funciones (...). En su aspecto más bien sustantivo, se lo asume como un estándar o patrón de justicia que guía el actuar de los órganos del Estado, considerando las

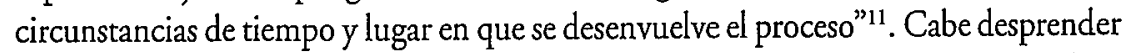
entonces, que el respeto del derecho al debido proceso, no consiste sólo en verificar que se acate dicha legalidad procesal, sino que superlativamente, $y$ con independencia de ella, que haya respeto por lo requerido en la Carta Fundamental". ${ }^{12}$

"En otras palabras, no basta para respetar el debido proceso con ceñirse a la ley que dispone determinado procedimiento, sino que respetando y aplicando los principios de supremacía constitucional y fuerza normativa de la carta fundamental, conforme a su articulo $6^{\circ}$ incisos $1^{\circ} \mathrm{y} 2^{\circ}$, tiene que siempre comprenderse y aplicarse que, el debido proceso, en cuanto derecho fundamental, no lo establece -sólo regula- la ley, sino que se encuentra reconocido y se exige su respeto desde el máximo nivel del Ordenamiento Jurídico Nacional, que se encuentra en la Constitución". ${ }^{13}$

En tiempos remotos entonces quedaron guardados los efectos del constitucionalismo de Estado “(...) en el que la Carta Fundamental, nada más que programática, quedaba entregada, en su secuela interpretativa y aun en la aplicación, a la potestad legislativa sin más" ${ }^{1}$. Así las cosas, "La vieja idea de legalidad se ve reforzada y, en parte, reemplazada por la de constitucionalidad"15, exigiendo "los preceptos fundamentales el respeto de condiciones formales y materiales $y$, desde luego, dentro de éstas últimas se encuentra (...) el que cuando se trate de la defensa de derechos fundamentales, las personas tengan derecho a un recurso sencillo y rápido"16.

En efecto, un derecho humano esencial, es el rápido acceso a la justicia, real y no reórico, pues de lo contrario, el derecho no es más que una linda declamación lírica en la cual se ampara una flagrante indefensión. Pero a esto hay que sumar, el que "Hoy en día, la duración del proceso se ha transformado en uno de sus principios informadores, ya que se parte del supuesto que si la decisión no es oportuna es igual a que si no la hubiere" ${ }^{17}$, por lo tanto, "si la sentencia no es oportuna, no se cumple con los principios del debido proceso, ya que los sujetos involucrados frente a un conflicto necesitan contar con una solución". ${ }^{18}$

Cea Egaña, José Luis, "La igual Protección de los derechos", en Revista Chilena de Derecho Volumen 9 № 3 , Santiago, Poncificia Universidad Católica de Chile, 1982, pág. 527.

1 Considerando $7^{\circ}$ de la sentencia pronunciada por la Corte Suprema el 31 de enero de 2003, reproducida en Varas Alfonso, Paulino, artículo cirado supra nora 2, pág. 36.

12 Fernández González, Miguel Ángel, "El derecho Constitucional al Debido Proceso con Especial Aplicación al Nuevo Proceso Penal", en Anales de la Facultad de Ciencias Jurídicas y Sociales No 2, Santiago, Universidad de Chile, 2005, pág. 84.

13 Id.

14 Fernández González, Miguel Ángel, "La nueva Justicia Penal Frente a la Consritución", Santiago, Ed. Lexis Nexis, 2006, Pág. 28.

15 Colombo Campbell, Juan, obra citada en supra nota 6, pág. 115.

16 Fernández, Miguel Ángel, obra citada supra nota 14, pág. 79.

17 Colombo Campbell, Juan, obra citada en supra nota 6 , pág. 118.

18 Id. 
En armonía con el criterio material que asisre al debido proceso en razón del fenómeno de la constitucionalización, cabe puntualizar otras dos importantes reglas de interpretación que se conjugan con aquel concepto. En primer lugar, "El interprete debe ajustarse a la pauta hermenéutica que enuncia el artículo 19 número 26 de la Constitución (...) de manera que jamás podrá interpretarse una disposición constitucional de tal modo que resulte lesionado o afecrado en su esencia un derecho fundamental humano." En segundo lugar, y complementando la regla anterior, "(...) deben descartarse de plano las interpretaciones que conduzcan al absurdo o a la falta de solución real o efectiva del problema suscitado (...) la existencia potencial de lagunas y contradicciones constitucionales no puede servir como excusa para que el intérprete se exonere de su responsabilidad fundamental de "decir el derecho"19.

Recapitulando escollos y conceptos esbozados, el trasfondo del problema que se presenta, es hasta dónde y cómo debemos evaluar el papel de la ley en el debido proceso, es decir, cabe preguntarse qué ocurre en aquellos casos en que el legislador nada ha dicho respecto a un procedimiento a seguir. Serán la hermenéutica constitucional ${ }^{20}$ y la misma concepción material ${ }^{21}$ las que brindarán la respuesta adecuada, toda vez que, en la cultura jurídica que en nuestros tiempos nos asiste -constituida por un cambio hacia un nuevo eje constitucional, a saber, el respeto y protección de la persona-, el primer punto a asentar, es que el inicio y la médula de este derecho al debido proceso, reconocido a todas las personas, consiste en que toda sentencia que pueda afectar sus derechos, debe ser dictada en un marco de justicia y equidad, marginando cualquier posibilidad que importe la indefensión. Por demás, una comprensión contraria del debido proceso significaría el abierto desconocimiento de lo dispuesto en el artículo 8 de la Convención Americana sobre Derechos Humanos -llamada Pacto San José de Costa Rica-, que prescribe el derecho de toda persona "a ser oída, con las debidas garantías y dentro de un plazo razonable, por un juez o tribunal competente, independiente e imparcial, establecido con anterioridad por la ley, en la sustanciación de cualquier acusación penal formulada contra ella, o para la determinación de sus derechos y obligaciones de orden civil, laboral, fiscal o de cualquier otro carácter".

20 La Comisión de Estudio avizoraba el sentido material de este derecho, dado que para la redacción del correspondiente numeral, se planteó que "si se ponía la expresión debido proceso, podría interpretarse que lo que es debido es lo que está en la ley, y lo que se debe hacer es lo que ha dicho la ley. Entonces resultaría un poco restringido y podría interpretarse a sí mismo en forma limitada. Por eso, se consideró adecuado agregar las expresiones racionalidad y justicia. En Evans de la Cuadra, Enrique, "Los Derechos Constitucionales" Tomo II, Santiago, Ed. Jurídica de Chile, 1999, Pág. 28.

21 Las directrices del derecho comparado, apuntan a la destacada sustancialidad. En España, el Tribunal Constitucional, en la aplicación del principio antiformalista, parte de la admisión que la libertad del legislador importa imponer los cauces $y$ formas procesales oportunas, que ordenen los medios de turela de los derechos e intereses legítimos, (...)Y es que el TC español sostiene una interpretación finalista, acorde con la cual, resulta evidente que el legislador no goza de absoluta libertad, "ya que constitucionalmente no son admisibles aquellos obstáculos procesales que puedan estimarse excesivos, que sean producto de un innecesario formalismo y que no se compaginen con el derecho a la justicia, que promuevan la indefensión o que no aparezcan justificados $y$ proporcionales conforme a las finalidades para las que se establecen, que deben ser en todo caso, adecuadas al espíritu constitucional. Cabe precisar que el artículo 24 , símil de nuestro $19 \mathrm{n}^{\circ} 3$, del cual el TC español predica una visión sustancial, reza lo que sigue: 1 . Todas las personas tienen derecho a obtener la tutela efectiva de los jueces y tribunales en el ejercicio de sus derechos e intereses legítimos, sin que, en ningún caso, pueda producirse indefensión. 2. Asimismo, todos tienen derecho al Juez ordinario predeterminado por la ley, a la defensa y a la asistencia de letrado, a ser informados de la acusación formulada contra ellos, a un proceso público sin dilaciones indebidas $y$ con todas las garantías (...)". 
En línea a la importancia que para la concreción de la igualdad importa este derecho, el constituyente quiso dar una fuerte cláusula de garantía, reforzando la reserva legal en materia de defensa jurídica y debido proceso. Pero eso no significa que haya postergado el acceso a la justicia o suspendido el derecho fundamental al debido proceso, en espera eterna de la gloriosa dictación de la ley. En el nuevo paradigma jurídico en el que vivimos, la Constitución es un texto teleológico, con finalidad, respetuoso y promotor de la dignidad humana y derechos fundamentales. No es un texto de formas absolutas, las que en tanto vestimentas del derecho, si bien en función de la certeza jurídica no deben ser eliminadas radicalmente, no pueden constituir la camisa de fuerza de aquellos valores que el constitucionalismo de la posmodernidad impulsa a realizar.

La ley, sin duda, en cuanto resultado de la discusión democrática, es uno de los pilares más trascendentes de nuestro ordenamiento y cultura jurídica, pero no debe olvidarse que en razón de la supremacía constitucional, es un concepto e institución instrumental para la defensa y protección de los derechos humanos, más precisamente, de la persona. Y es por eso, que supeditar el conocimiento de la nueva acción de inaplicabilidad a la dictación de la ley, importaría desnaturalizar la función a la que está llamada, favoreciendo la denegación de justicia bajo el amparo de una hermenéutica literalista y una concepción formal del debido proceso y la defensa jurídica.

\section{Debido proceso y el control difuso de constitucionalidad}

En ejercicio de la atribución que le otorga el artículo $93 n^{\circ}$ 6, el Tribunal Constitucional ha dictado diversos fallos declarando la inaplicabilidad. La doctrina ha señalado los procedimientos que posteriormente debieran ser regulados por la Ley Orgánica Constitucional respectiva ${ }^{22}$, y en especial, los jueces de garantía ya han comenzado a hacer uso del juicio incidental de constitucionalidad, consagrado en el inciso 11 del artículo citado. Cabe entonces hacerse la siguiente pregunta: ¿podemos afirmar que en Chile existe el control difuso de constitucionalidad, en circunstancias que, a diferencia del control concentrado de inaplicabilidad, aquel no está expresamente mencionado ni cuenta con una norma legal que regule el debido proceso en su ejercicio?

La doctrina abraza diversas posturas, y la balanza a favor de alguna de ellas no puede verse inclinada en razón del texto expreso del artículo 93. En efecto, quienes sostienen la existencia del control difuso por parte de los jueces que conocen del asunto, plantean que este tipo de control se fundamentaría en que el texto constitucional faculta y no obliga al juez a deducir el juicio incidental, pues el precepto en cuestión, en su inciso

22. "Procedimiento en que la Ley Orgánica del Tribunal Constitucional deberá contemplar las Garantías del Debido Proceso: 1. En el juicio de inaplicabilidad por inconscitucionalidad: 5.1.1.: Procedimiento de Declaración de Admisibilidad de la Acción de inaplicabilidad en lo no previsto en la Constitución. 5.1.2. Tramiración de la Suspensión del Procedimiento en que se haya originado la acción de la inaplicabilidad. 5.1.3: Procedimiento de Declaración de la inaplicabilidad del Proceso Legal contrario a la Conscitución 5.1.4: Procedimientos que deberán seguirse si la "cuestión" de inaplicabilidad es "planteada por cualquiera de las partes o por cl juez que conoce del asunco" a que se refiere el inciso 11 del actual artículo 93 de la Carta Fundamental". En Varas Alfonso, Paulino, arcículo citado supra nota 2, Pág. 36. 
$11^{\circ}$, prescribe que el juez "podrá" plantear la cuestión. La postura contraria, esto es, la que rechaza aquel tipo de control, arguye por su parte que ahora existe un texto constitucional expreso, que le indica al juez qué debe hacer en caso de dudas acerca de la constitucionalidad en la interpretación de un precepto legal.

En vista de la anterior situación, en los siguientes apartados, se intentará dar con la respuesta que más se conforme al espíritu del texto constitucional, en base a la aplicación de herramientas y principios de la hermenéutica constitucional.

\section{Argumentos a favor del control difuso de constitucionalidad}

Se argumenta que en razón del artículo $6^{\circ}$ de la Constitución, los jueces en tanto órganos del Estado, están obligados a preferir la Constitución a una norma inferior $y$, por consiguiente, a inaplicar los preceptos legales inconstitucionales. El artículo 6, en este punto, no fue cambiado por la reforma, por lo que si antes existía la posibilidad de control difuso, esa posibilidad se mantiene hasta hoy en día. En dicho contexto, el nuevo artículo 93 vendría a aclarar la situación, pues otorga al juez una facultad de consultar sus dudas de inconstitucionalidad, pero no lo obliga a hacerlo. Esta solución sería de toda lógica, pues, quien califica la necesidad de consultar, es el juez de la causa, en tanto él decide si tiene dudas o no acerca de la constitucionalidad. Más aún, aunque el artículo 93 estableciera la obligación de plantear la duda ante el T.C., bastaría que el juez de la gestión pendiente decidiera no consultar para él mismo aplicar directamente la Constitución, inaplicando la ley. ${ }^{23}$

\section{Análisis crítico}

A modo de primer asunto, surgen algunas interrogantes respecto a la extensión que da esta postura al artículo 6 . En efecto, en aquella norma se arraigan diversos principios constitucionales -Estado de derecho, supremacía constitucional, aplicabilidad directa, fuerza normativa, entre otros-. No obstante y considerando el rico contenido doctrinario del precepto, parece un tanto aventurado entenderlo como una norma de atribución de competencias, cuestión que va implícita en la teoría del control difuso, pues tal hipótesis jurídica sostiene que la disposición que otorga al juez, la atribución y facultad para inaplicar un precepto inconstitucional, se encontraría fundada y dispuesta en el referido artículo 6.

En particular, la primera interrogante, es si acaso esta disposición se presentaría como una norma competencial demasiado abierta, pues ¿a qué órganos se faculta en razón del artículo 6, para desconocer una ley que es interpretada por el mismo órgano como contraria a la Constitución? Aun cuando la respuesta se acotara a los órganos que ejercen

23 En Chile, defienden principalmente esta postura, los profesores Miguel Ángel Fernández Gonzáles, Lautaro Ríos Álvarez y José Ignacio Martínez Escay. 
jurisdicción, el escenario seguiría siendo bastante amplio. En razón de una interpretación sistemática que importe una relación entre los artículos 6 y 93 inciso $11^{\circ}$, podría entenderse limitado el control difuso a los jueces ordinarios y especiales que establece nuestra legislación, no obstante, podría ser un tanto arriesgado permitir el control difuso por parte de aquellos, pues se pone en riesgo la presunción de constitucionalidad de la ley y como veremos, la estabilidad del ordenamiento jurídico.

Sin perjuicio de las bondades y defectos que se apreciarán respecto del control difuso, cabe adelantar, que pareciera ser que hay dos conceptos que permitirian dilucidar acerca de la pretensión competencial del artículo 6 de la Carta Fundamental, a saber, el de deber y de atribución. En efecto, todo órgano, persona, institución o grupo, se encuentra obligado por los preceptos constitucionales, pero la forma de cumplir con dicho deber, varía de acuerdo a las atribuciones que sean otorgadas por la Constitución o la ley en conformidad al artículo $7^{\circ}$. En base a lo anterior, se avizora que en realidad la palabra "podrá", puede interpretarse de tres maneras diversas. En primer lugar, con el carácter de facultad absoluta, es decir, quedaría completamente al arbitrio del juez iniciar el juicio incidental; en segundo término, puede entenderse como facultativa para el caso en que el juez tenga la fehaciente convicción de que la interpretación del precepto resulta contraria a la Constitución, situación ante la cual, podría él mismo inaplicar la norma; finalmente, puede entenderse que el mencionado vocablo, importa siempre la obligación de solicitar la declaración de inaplicabilidad para el juez que conoce el asunto. Al parecer, esta última interpretación, es la interpretación que desde la perspectiva finalista y sistemática más se ajusta al espíritu de la Constitución, en orden a las siguientes consideraciones y ventajas que han de destacarse.

Como punto de partida -y es algo que ya aclaramos y en que estamos contestes-, el juez, en razón del artículo 6 , se encuentra obligado a velar por la supremacía constitucional, y el primer análisis se hará considerando el elemento sistemático de interpretación, en tanto permite discernir las relaciones entre diversos preceptos, para fijar la finalidad de éstos y las normas que a ellos se adscriben. Dos consideraciones envueltas en dicha regla interpretativa fijan la ruta que encamina a decantar la cuestión, a saber, la distinción entre parte dogmática y orgánica del texto constitucional, y el que valores y principios en aquella recogidos, infunden el alma, preceptos y normas de la parte orgánica de la Constitución ${ }^{24}$. Por consiguiente, es del caso vislumbrar la relación entre los artículos 6 y 93 , apuntando a que es el primero de ellos, en tanto recipiente de principios y valores, el que fija el sentido y alcance del segundo ${ }^{25}$, en cuanto norma orgánica de atribuciones. Atendido lo anterior, se desprende que en circunstancias de haber sido dotado el juez de la causa, por la reforma constitucional,

24 Respecto a los elementos y criterios de interpretación constitucional, consúltese la obra ya citada de Patricios Zapata Larrain "La Jurisprudencia del Tribunal Constitucional".

25 Véase en ente punto Cea Egaña, José Luis, "Derecho Constitucional Chileno", Tomo II, Santiago, Ed. Universidad Católica de Chile, 2004, pp. 38 - 44. 
de una atribución expresa y de explícito ejercicio, éste se ve obligado en razón del artículo 6 y la supremacía constitucional, al desempeño de tal atribución, pues ha sido llamado especialmente por la Carta fundamental a colaborar y garantizar el respeto y plena vigencia de nuestra Ley Suprema. Serán razones de igualdad y certeza jurídica, las que imponen aquella dirección.

En efecto, el asunto de fondo es determinar si el control difuso constituye o no una mayor garantía para la protección de los derechos fundamentales de acuerdo a una interpretación finalista y armónica de la Constitución. Y es que la directriz interpretativa y más importante de todas, cual deriva del artículo $1^{\circ}$ inciso $1^{\circ}$, es el principio hermenéutico que busca la comprensión más favorable a la dignidad y los derechos de la persona humana ${ }^{26}$, siendo a su vez este principio, la sólida base sobre la cual habrá de determinarse la debida correspondencia y armonía de la normativa constitucional.

Ahora, visto el asunto desde el cristal de aquella regla interpretativa, no son tan meritorias las ventajas que presenta el control difuso. En efecto, una de las críticas que se hace a este tipo de control, propio de los Estados Unidos, es que con él se quebranta la interpretación uniforme de la Constitución, cuestión que en los hechos, se ve aminorada en aquel país del Norte por la existencia del precedente. En Chile, en cambio, la situación es distinta: no tenemos aquel paliativo, $\mathrm{y}$ al fin $\mathrm{y}$ al cabo, el quebrantamiento o falta de uniformidad en la interpretación del Código Político, producto de la propia interpretación que pueda efectuar cada juez, importará la desigualdad de los ciudadanos ante la Ley Fundamental, con la consiguiente falta de certeza jurídica, y a la larga, de estabilidad constitucional. Ya afirma la doctrina que "interpretar la Constitución, es interpretar una norma jurídica, pero de especiales características, vinculada siempre a situaciones particulares de cada etapa histórica determinante en la organización política de un país. (...) En este entendido, la interpretación constitucional ha de orientarse a mantener el principio de la seguridad jurídica y la vigencia del Estado de derecho." ${ }^{27}$

Reafirma esta visión un breve análisis del elemento histórico, es decir, de los anhelos a que obedeció la consagración de reforma en análisis. En el primer informe de la Comisión del Senado ${ }^{28}$, se escuchó la opinión del profesor Juan Colombo Campbell, quien expresó: "que en doctrina, hay en el mundo dos grandes sistemas de control constitucional, uno que se conoce como control difuso y otro, como control concentrado. Explicó que en el control difuso todos los tribunales ordinarios de la República tienen

Véase el arcículo de Henriquez Viñas, Miriam, "Evolución de la Jurisprudencia en Torno al Artículo 5 inc. 2 de la Consticución", en el cual su autora alude a la adecuada aplicación del criterio hermenéucico aludido. En Anuario Facultad de Ciencias Jurídicas, Copiapó, Universidad de Atacama, año 1 (1), 2003, Pág. 67.

${ }^{27}$ Colombo Campbell, Juan, obra citada supra nora G, Pág. 73.

28 En primer informe al Senado de la Comisión de Constitución, Legislación, Justicia y reglamento, recaido en mociones de los HH. Senadores señores Chadwick, Diez, Larraín y Romero, y de los HH. Senadores señores Bitar, Hamilton, Silva y Viera-Gallo, con las qque inician sendos proyectos que introducen diversas reformas a la Carta Fundamental. Bolerines Nos 2.526-07 y 2.534-07. 
que aplicar primero la Constitución y después la ley. En el control concentrado, hay uno o más tribunales que exclusivamente tienen el control de la constitucionalidad, fundamentalmente de las leyes, pero también de los decretos e incluso de las sentencias. Al control difuso, puntualizó, la crítica que se le formula es que todos los jueces pueden interpretar la Constitución y hacerlo de manera distinta".

Por su parte, la doctrina ha estado conteste en sostener la necesidad de uniformar la interpretación jurisprudencial: "En resumen, el ordenamiento constitucional chileno ha dado -como se dice- un salto cualitativo, desde una jurisdicción constitucional mixta y segmentada entre dos órganos, a una jurisdicción plena y-unitaria radicada en el T.C. (...). Con todo, el progreso que se espera tiene un alcance superior, que consiste en poner fin a la dualidad de visiones, anterior a la reforma, en virtud de los distintos criterios hermenéuticos con que la Corte Suprema y el T.C. interpretaban la Carta Fundamental. La unidad de criterio interpretativo que asegura un tribunal especializado, deberá reestablecer la certeza, la seguridad jurídica en esta importante materia"2. "Si bien, uno de los contralores era abstracto (el del TC) y el otro concreto (la inaplicabilidad), la duplicidad de controles no favorecía la coherencia e integridad de la Constitución". 30

Siguiendo este orden de ideas en cuanto a la necesaria uniformidad de nuestra jurisprudencia constitucional, incluso en aquellos casos en que la interpretación, o más aún, la disposición en sí, adoleciera de una manifiesta inconstitucionalidad, el juez está obligado a formular el juicio incidental, puesto que de esta manera, su actitud se conformará con màyor fuerza al mandato del artículo 6 de la Constitución, ya que mediante la consulta de inconstitucionalidad colaborará para que posteriormente el T.C., sea de oficio o en razón de la acción pública, expulse definitivamente el precepto inconstitucional del ordenamiento jurídico, cuestión que sin duda, fortalece la certeza jurídica y la igualdad en y ante la ley.

Tal vez, con anterioridad a la reforma, al no existir la nueva analizada atribución del juez del asunto, el principio hermenéutico de protección de la dignidad y derechos humanos, podría haber inclinado la balanza hacia el control difuso. Pero ya en estos momentos, los jueces cuentan con una herramienta clara, con una atribución expresa, otorgada por el Constituyente derivado, en orden a colaborar por el respeto al principio de supremacía constitucional. En efecto, "la presencia del Tribunal Constitucional, y sus facultades de control de constitucionalidad sobre las resoluciones judiciales, da a cada juez y a cada tribunal, un papel destacado y especialmente importante en la democracia. A sus funciones de resolver conflictos conforme a derecho que históricamente han tenido, tiene que agregar ahora la importantísima función de garantizar

30 Gómez Bernales, Gastón, "La reforma Constitucional a la Jurisdicción Constitucional" contenido en Francisco Zúniga Urbina (Coordinador) "Reforma Constitucional", Santiago, Ed. Lexis Nexis, 2006, pág. 652. 
que los derechos fundamentales sean reales y efectivos con la seguridad de saber que sus actuaciones estarán respaldadas por un órgano técnico independiente, ya que el juez que conoce del asunto, como dice el art. $93 \mathrm{CPR}$, está facultado para plantear directamente la cuestión de inconstirucionalidad ante el Tribunal Constitucional. Por eso se puede decir con propiedad que los jueces chilenos, con las nuevas competencias que tiene el Tribunal Constitucional y con la facultad de plantear directamente cuestiones de constitucionalidad, han pasado a constituirse en garantes de los derechos iusfundamentales". ${ }^{31}$

A lo anterior puede sumarse, el que la Corte Suprema razona dentro del paradigma de protección de la ley, en cuanto su funcionamiento está enmarcado bajo el mecanismo del recurso de casación. Esto explicaría en cierta forma por qué la inaplicabilidad no presentó un destacado desarrollo cuando estuvo bajo su competencia, y a su vez, lleva a cuestionar la idoneidad que tendría el juez que conoce del asunto para salirse de aquel esquema. En ese sentido, la reforma envuelve una característica interesante, ya que " $\mathrm{El}$ modelo de jurisdicción constitucional que crea la reforma hace compatibles, de una parte, la supremacía constitucional y los derechos fundamentales que debe asegurar el TC y, de la otra, la obligatoriedad de la ley que pesa sobre el juez de fondo, en la medida de que éste no puede inaplicar la ley de oficio ni a petición de parte (...)"32.

\section{Consideraciones finales}

El Tribunal Constitucional, pese a no haberse dictado la Ley Orgánica Constitucional en cumplimiento de lo dispuesto en el inciso final del artículo 92, comenzó a conocer y resolver las acciones de inaplicabilidad, en salvaguarda de los principios constitucionales matrices, y sobre los cuales ha de sustentarse el ordenamiento jurídico entero.

Analizadas las atribuciones que se otorgan en el artículo 93 número 6 y en el inciso 11 del mismo artículo, desde distintos criterios interpretativos constitucionales se evaluó la posibilidad de que existiera en Chile, después de la reforma, un control difuso de constitucionalidad, paralelo al control concentrado que efectúa el Tribunal Constitucional.

Las distintas reglas y principio hermenéuticos, como resulta ser la protección de la dignidad y derechos fundamentales, el elemento de la historia fidedigna, el espíritu de la reforma y el criterio sistemático, que sobrepasan a una interpretación literalista del artículo en cuestión, alejaron la posibilidad de un control difuso, toda vez que éste atentaría fundamentalmente en contra de la igualdad en y ante la ley, con el concomitante perjuicio al bien de la certeza jurídica.

31 Hormazábal Malarée, Hernán, "El Nuevo Tribunal Constitucional: los Derechos Fundamentales y el Moderno Recurso de Inaplicabilidad", Ed Lexis Nexis, Santiago, 2006, pág. 114.

32 Gómez Bernales, Gastón, artículo citado supra nota 28, pág. 652. 
Cabe anhelar que, a futuro, la nueva atribución concedida a los jueces contribuya a forjar su carácter y labor, en orden a ser partes del proceso de constitucionalización del derecho y de la defensa activa de la ley fundamental; principalmente, de los derechos fundamentales, razón de ser de los actuales ordenamientos constitucionales. 